\title{
Method for Determining the Optimized Exhaustion of Fatliquors to Minimize the ETP-inflow
}

\author{
Dirick Von Behr
}

Smit \& zoon, 1382 LK Weesp, Netherlands

Copyright $\mathrm{O} 2018$ by authors, all rights reserved. Authors agree that this article remains permanently open access under the terms of the Creative Commons Attribution License 4.0 International License

\begin{abstract}
The proposed amendment of the German regulation for the treatment of tannery wastewaters (ATV-DVWK-M774-proposal 2015) emphasizes minimization of the pollution burden before treatment (inflow) [1]. Current regulations are directed towards setting limits to what may leave an ETP (outflow). The new provisions, on the other hand, demand that a verifiable reduction of the polluting load is realized before the water enters the treatment system. An absolute decrease at the level of individual components requires the measurement of these components for a starting point. This paper discusses the ways of expressing the exhaustion of a selection of fatliquors on chrome and chrome-free leathers. Each product has a specific affinity to the tanned hide and an individual environmental imprint. This specificity can be used for targeted reduction of the inflowing pollution burden. The findings of the study can act as a starting point for setting up an own methodology and a detailed level of reporting for all who need to understand a fatliquor's true affinity towards the leather and those who endeavor to minimize the environmental impact of their processing.
\end{abstract}

Keywords Exhaustion, Environment, Fatliquor, Chrome, FOC, ETP

\section{Introduction}

In the leather manufacturing process, raw hides undergo a series of pre-treatments that may include soaking, (green) fleshing, unhairing, liming, lime splitting, deliming, bating, degreasing and pickling before the cleaned and altered collagen structure enters the tanning stage. Tanning alters animal collagen, the main component of skin in such a way that renders it resistance to heat and microorganism attack, which can be generally characterized by rises in the hydrothermal stability (shrinkage temperature) of the material.

For further modification of the leather properties, tanning is followed by retanning, dyeing and fatliquoring.
Retanning modifies and improves the leather structure while dyeing gives the desired colour. Fatliquoring is the treatment of leather with emulsified oils to give it lasting softness after it has been dried $[2,3,4,5]$.

The largest input in leather processing is from water, with a higher consumption by rawhide weight than any other process ingredient $[6,7]$. As a result considerable amounts of wastewater are generated, demanding high investment and operational costs for effluent treatment to satisfy the discharge standards required by environmental legislation [8].

The constitution of untreated effluent float depends on composition, quantities and manufacturing of the chemicals used during the upstream process. Effluent constitution depends on the type of processing in the tannery: the effluents of wet blue producers are different from those of tanneries that process from raw hides to finished leathers, which in turn are of other constitution than the floats from producers that work from tanned stock and limit themselves to crusting and finishing [9].

Liming and tanning yield effluents of more or less known composition, but the inclusion of retanning, fatliquoring and dyeing makes matters trickier due to the wide chemical range of the products $[10,11]$ applied and the very complex variety of mixtures in the discharged floats.

Rules and regulations with respect to the treated effluent discharged have been based on its outflow into the environment. The quality of the water that enters an ETP is of concern to the operators and not to the authorities.

Newer regulations state that the volume of sewage and contaminant load is to be kept as low as possible by actively reducing the contaminant load in the raw wastewater in wet-end process by the optimizing retanning, dyeing and fatliquoring [1].

Whereas in the past it sufficed to demonstrate that the outflow from an ETP met with the specific rules and regulations of the local authorities, future requirements will include the need to demonstrate that active efforts have been taken to reduce the inflow's pollution burden prior to treatment [1]. 
The treatment of the discharged float cannot be seen separately from the process it stems from [12]. Processing and effluent water may be identical but are in practice two different departments with little knowledge of each other and unequal levels of attention for their content. The operator of an ETP needs to treat the sewage received from the factory and may not need to have an in-depth knowledge of the effluent-generating processes, yet he or she needs to know what it is that the factory discharges.

The cost of wet-end chemicals discharged into an ETP is threefold and the user pays [13]

1. a price for the unused products

2. the operating cost for removing the unused products from the effluent

3. a fee for the disposal of the sludge

At the end of the wet-end processes in most cases the measure of exhaustion is the visible inspection of the spent floats and a judgement of their transparency and color [14]. A large variety of products creates a mixture of unknown constitution and consistency which can lead to fluctuations and failures in treatment and water quality. Knowing the quantities and of residual chemicals in waste water and their influence on water treatment allows easier and more economical operation of an ETP.

The results discussed in this paper are the outcome of a comparative investigation into fatliquors' affinity to both chrome (wet blue) and chrome free (wet white) tanned leathers with the purpose of finding tendencies and classifications to predict and control ETP-inflow and treatment. Based on the percentage exhaustion of individual fatliquors the fatliquors can be allocated in groups for their affinity for leathers of different tannage.

\section{Materials and Methods}

\subsection{Materials}

In this study chrome-tanned bovine hides of 1.1-1.2 $\mathrm{mm}$ and glutadialdehyde-pretanned of 1.1-1.2 $\mathrm{mm}$ bovine hides were used. Both leather types had been produced for automotive application and have been processed according to the recipes in

Table 1. (wet white)

\begin{tabular}{|c|c|c|c|c|c|}
\hline Process & $\%$ & Product & $\mid \begin{array}{c}\text { Temp } \\
{ }^{\circ} \mathrm{C}\end{array}$ & $\begin{array}{l}\text { Drum } \\
\text { Time }\end{array}$ & $\mathrm{pH}$ \\
\hline wash & 300 & water & 30 & 20 & \\
\hline \multicolumn{6}{|l|}{ drain } \\
\hline \multirow[t]{2}{*}{ neutralizing } & 70 & water & 30 & & \\
\hline & 2 & sodium formate & & 30 & 4.8 \\
\hline \multirow[t]{3}{*}{ retanning } & +10 & Syntan DM 262 & & 30 & \\
\hline & +10 & Syntan S & & 330 & \\
\hline & +100 & water & 50 & 10 & \\
\hline \multirow[t]{2}{*}{ acidifying } & +1.5 & formic acid $(1: 10)$ & & 30 & \\
\hline & +1.5 & formic acid $(1: 10)$ & & 90 & 3.5 \\
\hline \multicolumn{6}{|l|}{ drain } \\
\hline wash & 300 & water & 35 & 10 & \\
\hline \multicolumn{6}{|l|}{ drain } \\
\hline \multirow[t]{2}{*}{ fatliquoring } & 100 & water & 50 & & \\
\hline & 14 & FATLIQUOR & & 60 & \\
\hline acidifying & +1 & formic acid $(1: 10)$ & & $10+20$ & 3.5 \\
\hline drain & & float sample - acidification & & & \\
\hline cold wash & 300 & water & 25 & 10 & \\
\hline drain & & float sample - final wash & & & \\
\hline
\end{tabular}


Table 2. (wet blue).

\begin{tabular}{|c|c|c|c|c|c|}
\hline Process & $\%$ & Product & $\begin{array}{c}\text { Temp } \\
{ }^{\circ} \mathrm{C}\end{array}$ & $\begin{array}{l}\text { Drum } \\
\text { Time }\end{array}$ & $\mathrm{pH}$ \\
\hline \multirow[t]{2}{*}{ wash } & 300 & water & 35 & & \\
\hline & 0.2 & formic acid (1:10) & & 15 & 3.6 \\
\hline \multicolumn{6}{|l|}{ drain } \\
\hline \multirow[t]{3}{*}{ neutralizing } & 100 & water & 35 & & \\
\hline & 2.5 & sodium formate & & & \\
\hline & 0.7 & sodium bicarbonate & & 45 & 5.5 \\
\hline \multicolumn{6}{|l|}{ drain } \\
\hline wash & 300 & water & 35 & 10 & \\
\hline \multicolumn{6}{|l|}{ drain } \\
\hline \multirow[t]{2}{*}{ retanning } & 100 & water & 35 & & \\
\hline & 12 & Syntan DM 262 & & 60 & \\
\hline acidifying & + & formic acid $(1: 10)$ & & $5+15$ & 3.8 \\
\hline \multicolumn{6}{|l|}{ drain } \\
\hline wash & 300 & water & 35 & 10 & \\
\hline \multicolumn{6}{|l|}{ drain } \\
\hline \multirow[t]{2}{*}{ fatliquoring } & 100 & water & 50 & & \\
\hline & 10 & FATLIQUOR & & 45 & \\
\hline acidifying & + & formic acid $(1: 10)$ & & $5+15$ & 3.6 \\
\hline drain & & float sample - acidification & & & \\
\hline cold wash & 300 & water & 25 & 10 & \\
\hline drain & & float sample - final wash & & & \\
\hline
\end{tabular}

Two identical series of commercially available automotive range fatliquors were applied for both applications: polymeric \& natural softeners (fatliquor 1), blend of sulphated and sulphited vegetable oils (fatliquor 2), lecithin (fatliquor 4), sulphated vegetable oils (fatliquor 11), blend of sulphited vegetable and animal oils with synthetic oil (fatliquors $3,8,9,10,12$ ), blend of natural oil with phosphated and succinic acid esters (fatliquors 5 \& 7), sulphited fish and animal oil (fatliquor $6)$.

\subsection{Methods}

The used processes differed in their design and were formulated considering the specific wet-end processing practices for the two different tannages. The percentages of fatliquor applied differ: 10\% applied for wet blue and 14\% application for wet white. Both processes represent simplified forms of commonly applied processes.

COD, BOD and TDS determinations were performed at external testing institutes according to ISO 6060:1989 (COD), ISO 1899-1:2003 (BOD) and STAS 9187-84 (TDS).
Further analyses carried out were TSS, TDS and BOD5. A fatliquor's possible contribution to TSS only stems from improper emulsification and is therefore related to the handling of the fatliquor and not the product itself.

Both TDS and BOD5 demonstrated the same patterns as found with the COD measurement. For this reason the focus of this paper is on COD only.

\section{Results \& Discussion}

Twelve commercially available fatliquors have been compared under identical conditions and acidified with a fixed amount of formic acid to the $\mathrm{pH}$ range of 3.5-3.7 for wet blue leathers and 3.4-3.6 for wet white leathers. All values have been based on a) the float before processing, b) the exhausted float after acidifying and c) the subsequent washing float.

For a first comparison the exhaustion has been expressed in the manner commonly used by the industry as percentage. This percentage relates to the original content of the float minus the residue after processing (original COD - residual COD $=$ exhaustion). 


$$
\% \text { exhaustion }=100\left(1-\frac{R a a+3 x R f w}{m 0}\right)
$$

$\mathrm{m} 0$ : COD of the original float before processing

Raa: COD of residue after acidification

Rfw: COD of residue of final washing

The washing value is multiplied by 3 since the washing float has a length of $300 \%$ as compared to $100 \%$ float length used for retanning or fatliquoring.

As can be seen from Figure 1, not only the exhaustion percentage between fatliquors greatly varies, but no general relation exists either between their use on $\mathrm{w} / \mathrm{b}$ and $\mathrm{w} / \mathrm{w}$.

Of the fatliquors with a higher exhaustion percentage $(<90 \%)$ nos. 1, 2, 10, 12 demonstrate comparable exhaustion percentages on both types of tannage, while with nos. $4,5,11$ the $\mathrm{w} / \mathrm{w}$ exhaustion is inferior to that of $\mathrm{w} / \mathrm{b}$. Fatliquors of a lower exhaustion percentage on $\mathrm{w} / \mathrm{b}$ without exception show inferior exhaustion percentages to varying degrees when applied on w/w.

Figures $2 \& 3$ illustrate how much the acidified bath contributes to the total percentage of residue, and how much of the residue has been released by the washing bath.

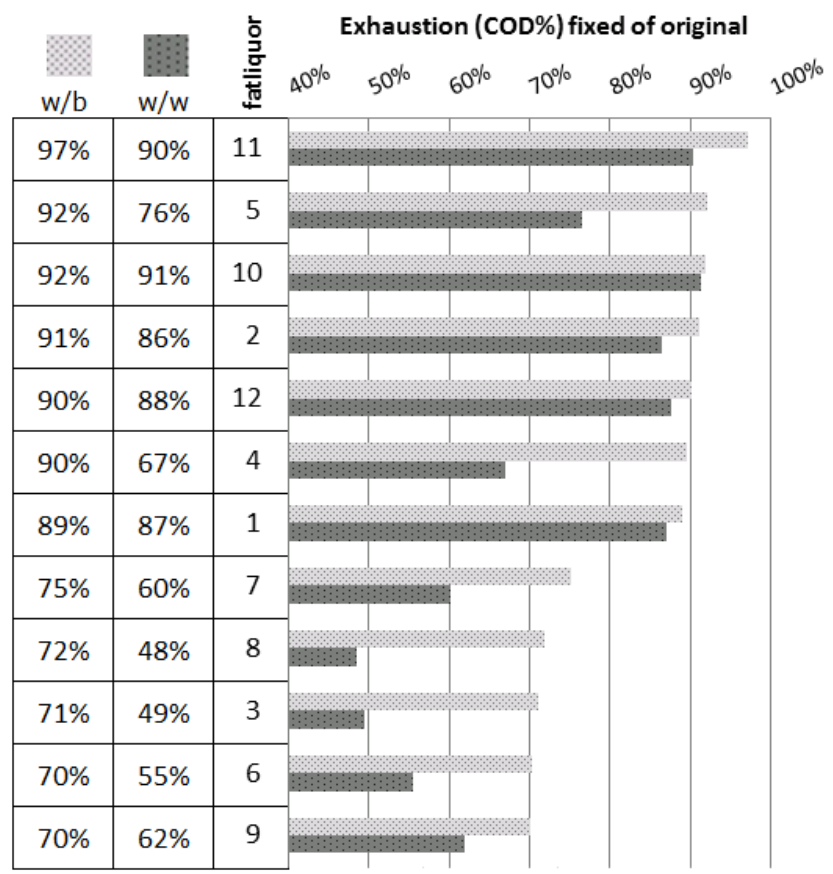

Figure 1. Exhaustion percentages of different fatliquors compared for wet blue and wet white processing

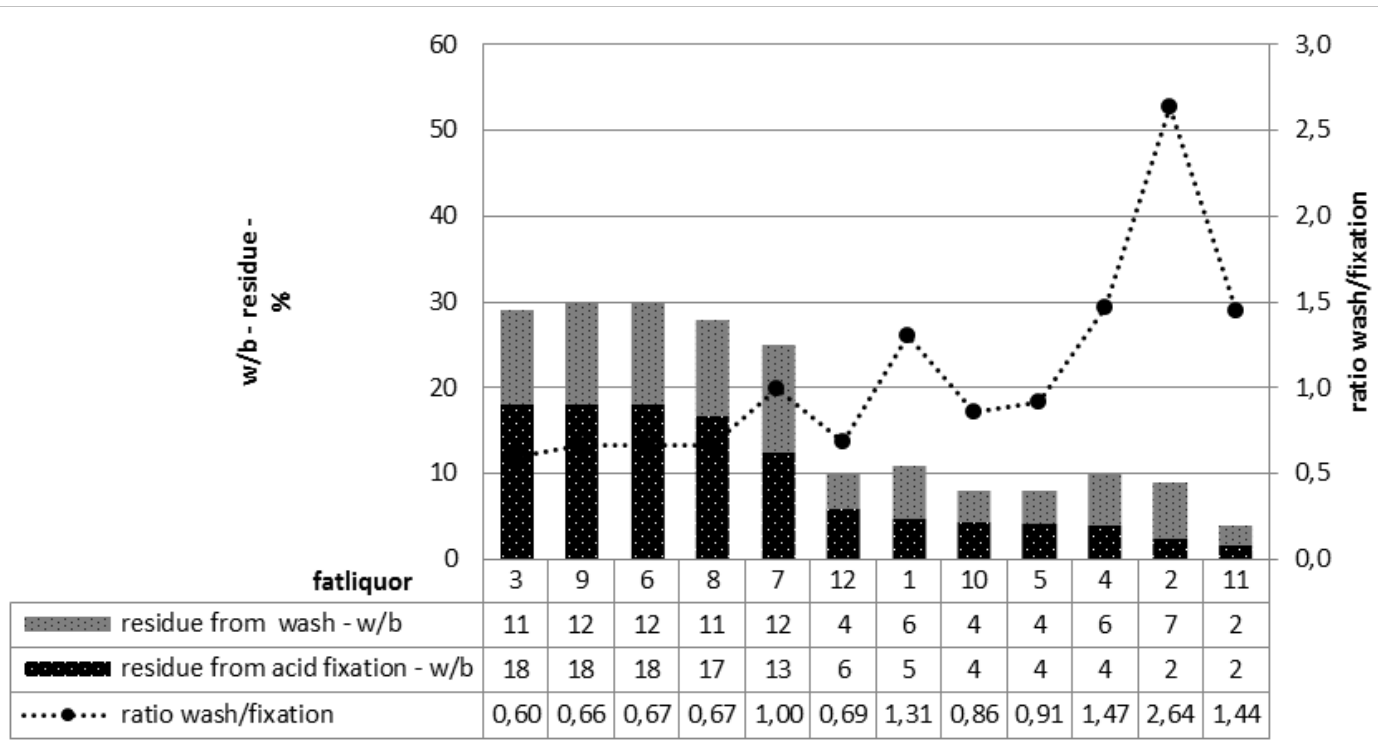

Figure 2. Percentage of residue generated by different fatliquors on wet blue stemming from the combined acidified and washing floats 


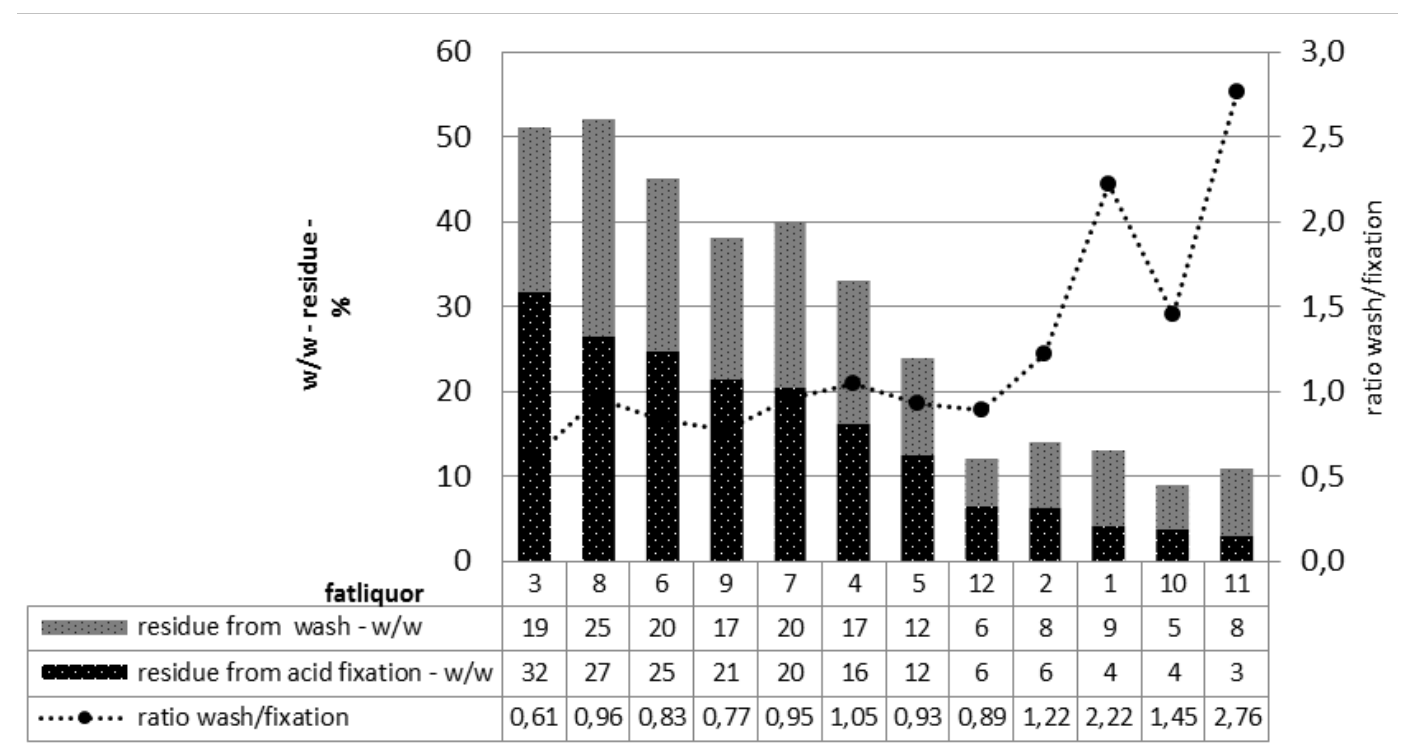

Figure 3. Percentage of residue generated by different fatliquors on wet blue stemming from the combined acidified and washing floats

Both figures evidence that with increasing amounts of residue in the acidified fatliquor bath the release of unused products from washing increases too.

The ratio between the residues from washing and fixation increases for products that leave only small amounts of residue in the drained float: the bulk of the residue stems from washing. For those fatliquors that leave a large amount of residue it is the other way round: the bulk of their residue stems from acid fixation.

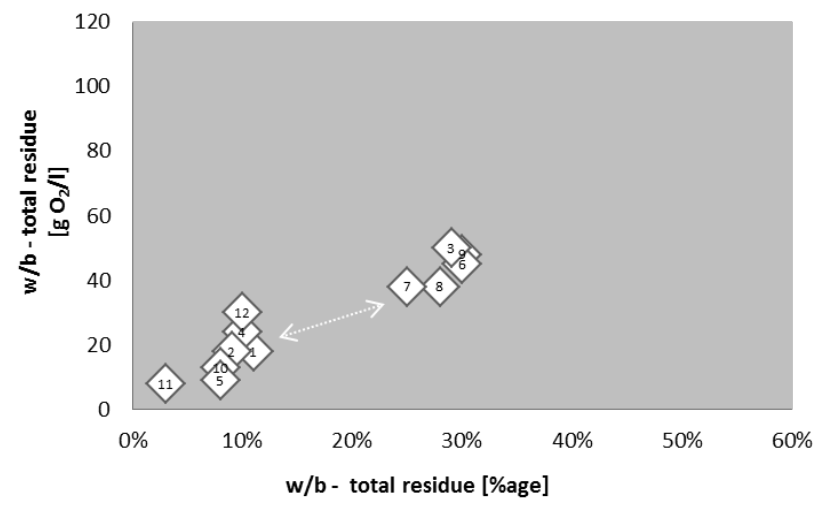

Figure 4. Percentage of residue on wet blue in relation to quantity of $\mathrm{O}_{2}$ required for oxidizing the residual fatliquor

In figures 4 and 5 the percentage of residue is contrasted to the oxygen amount needed for treating the residual float. It can be seen that equal percentages of exhaustion can represent different degrees of organic pollution. The tables have been prepared from lower to higher exhaustion percentages to make the conclusion more easily visible.

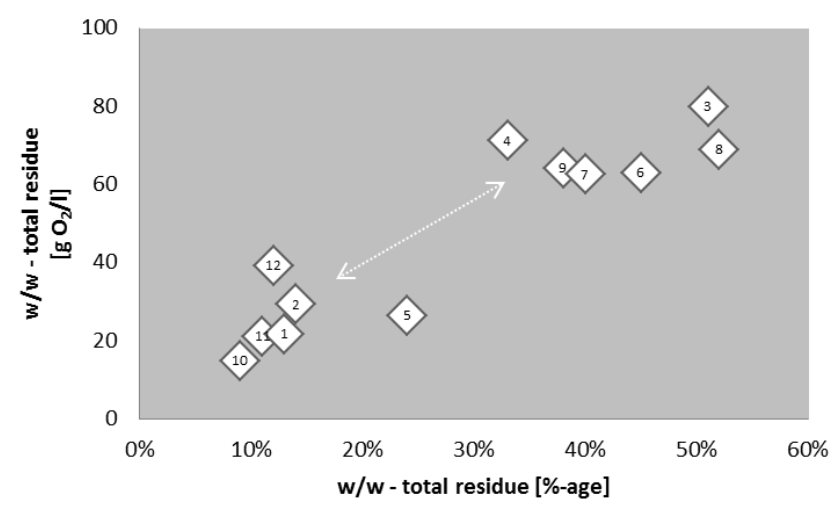

Figure 5. Percentage of residue on wet blue in relation to quantity of $\mathrm{O}_{2}$ required for oxidizing the residual fatliquor

The fatliquors show a particular grouping profile. When used on wet blue, the profiles are notably more specific than when they are applied on wet white.

In both cases a particular gap between the groups is visible.

The exhaustion percentage can also be expressed as a fatliquor's affinity for the substrate it is to react with.

None of the fatliquors shows a better exhaustion rate on wet white than on wet blue, while others show a reduced tendency for binding to wet white when compared to wet blue. 


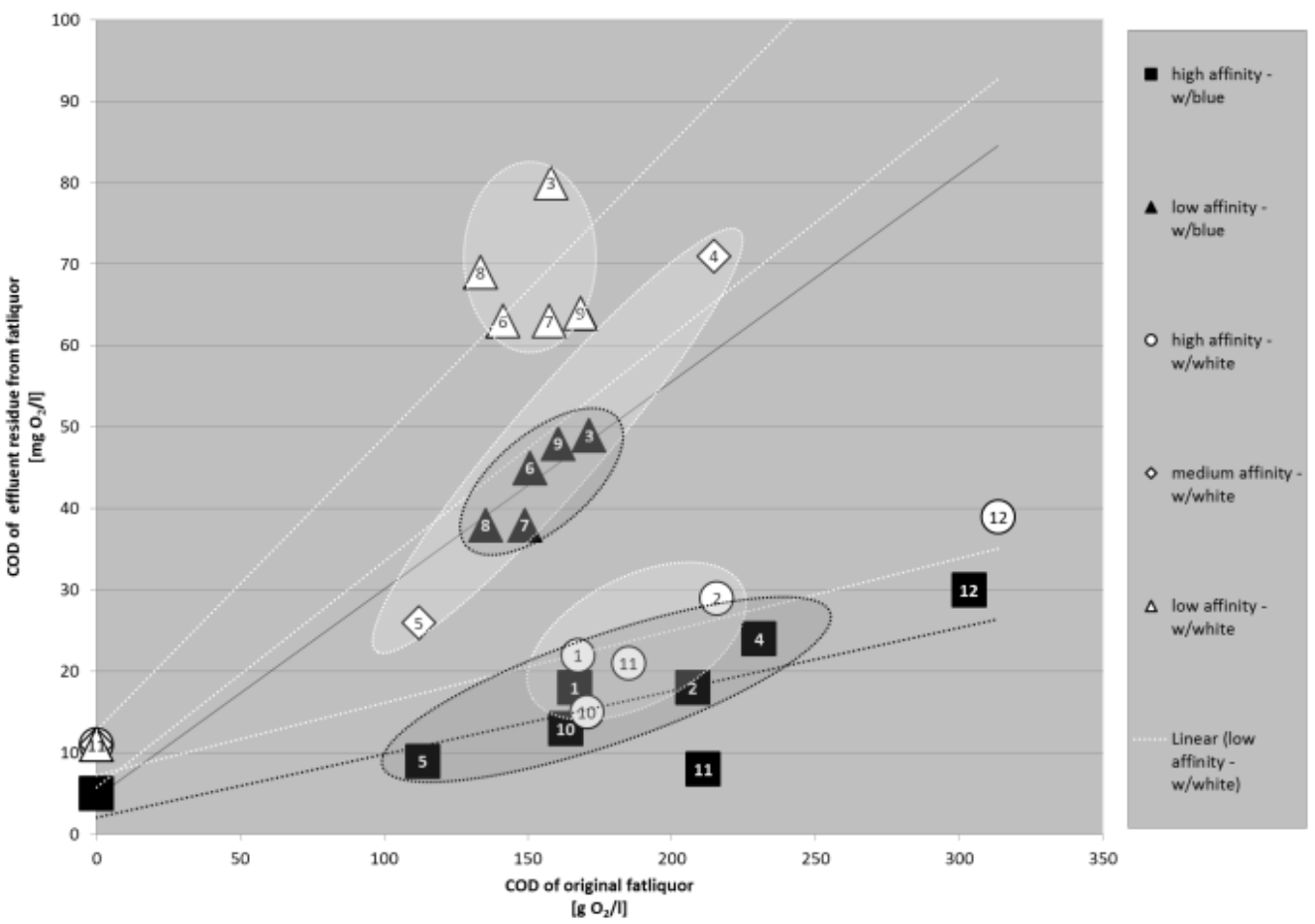

Figure 6. The quantity of $\mathrm{O}_{2}$ required for oxidizing the unused fatliquor in relation to the quantity of $\mathrm{O}_{2}$ required for oxidizing the residual fatliquor

From the effluent data a classification of fatliquors into affinity classes can be made when the individual fatliquor's residual COD is opposed to its initial and unconsumed COD.

The graphic contrasting of the unused fatliquor's initial COD with the COD of the residue it leaves behind does not show a random distribution of properties. Instead it brings to light distinctive groups representing the fatliquors' affinity to the tanned hide.

- Fatliquors of low affinity to both wet blue and wet white form clearly defined groups of comparable initial, unconsumed COD for the products before their use. They are only distinguished by the amount of residue generated by processing wet blue or wet white. The fatliquors of both groups are near- identical, whether used for wet white or wet blue.

- Fatliquors of high affinity to wet white are a clearly defined and fairly homogenous group. The height of their residual COD appears to be related to their initial, unconsumed COD.

- Fatliquors of high affinity to wet blue are less homogeneous in their behavior; their low residual COD value is less related to their initial, unconsumed COD value.

- Medium affinity is a classification that can only be applied when processing wet white. The group consists of too few fatliquors (2) of a too large band width to clearly identify them. There appears to be a general relation between their initial unconsumed COD value and the residue they generate in the spent floats.

- One fatliquor of high affinity to both wet blue and wet white is separated from all the rest.

\section{Conclusions}

Fatliquors to the greatest extent consist of organic compounds. Measuring the float's COD is sufficiently indicative of a fatliquor's degree of exhaustion and the residue it leaves in the drained float.

Based on COD measurements we find patterns that cannot be related to the origin and composition of the fatliquors used.

The commonly practiced method to express the exhaustion of fatliquors by the analysis of the exhausted fatliquor float alone overlooks the fact that what is believed to be fixation is to a large degree a reversible binding dependent on $\mathrm{pH}$. The clean float and the $\mathrm{pH}$ increase that come with washing can cause the further release of substantial amounts of fatliquor, some of them still unfixed and others previously fixed. For drawing relevant conclusions, washing floats are to be included in any calculation of the kind.

The thus calculated percentage of exhaustion still does not provide any information on the real degree of pollution generated by the residue of a fatliquor. A seemingly good exhaustion can generate considerable pollutant load while, on the other hand a lower exhaustion percentage can be relatively light in pollution burden. The 
exhaustion expressed as percentage therefore has no value to illustrate a fatliquor's quality in environmental terms.

To do so, the oxygen demand needed for converting the residual organic material is a far more suitable criterion to describe a fatliquor's environmental impact and compare it to the residues left by other oils.

The tendency to exhaust can be expressed as affinity towards the tanned hide. Of the fatliquors investigated none had a higher affinity for wet white than for wet blue. A small group shows comparable affinity, but most of the oils demonstrate considerably lower affinity.

Randomness appears when attempting to reduce a fatliquor's affinity to its composition or making. None of the affinities found can be attributed to the chemical composition or to any of its main constituents and appears to be a singular property of an individual fatliquor.

The research demonstrated that by applying a simple method and a specific juxtaposition of data yields consistent values to define the affinity of any product towards the tanned hide during processing and the pollution burden after its use. Further research would define whether this behavior depends on a fatliquor's chemical manufacturing and to any of its main constituents, or whether it is independent of this and is a singular property of an individual fatliquor.

\section{REFERENCES}

[1] ATV-DVWK-M774, Abwasser aus lederherstellenden Betrieben, proposal 2015
[2] Moog, G., Der Gerber - Handbuch für die Lederherstellung, 2005.

[3] Daniels R., The Framework for Leather Manufacture - An overview of leather manufacture, 2013.

[4] Faber, K., Bibliothek des Leders - Band 3 Gerbmittel, Gerbung, Nachgerbung, 1990

[5] Hollstein, M., Bibliothek des Leders - Band 4 Entfetten, Fetten und Hydrophobieren bei der Lederherstellung, 1987

[6] BulJan, J. Kral, I. The Framework for Sustainable Leather Manufacture working paper 2015

[7] Sundar, V. J. Ramesh, R. Rao, P. S. Saravanan, P. Sridharnath, B. Mulralidharan, C. Water Management in Leather Industry, Journal of Scientific \& Industrial Research, vol. $60, \mathrm{p} 443-450,2001$.

[8] de Aquim, P. M. Gutteres, M. Trierweiler, J. Assessment in Water Management in Tanneries: State of Rio Grande do Sul Case Study

[9] BulJan, J. Introduction to Treatment of Tannery Effluents, 2011.

[10] Heidemann, E. Fundamentals of Leather Manufacturing, 1993.

[11] Covington, A. D. Tanning Chemistry: the Science of Leather, RSC publishing, 2009.

[12] Daniels R., The Framework for Leather Manufacture - The Environment, 2013.

[13] Buljan, J. Kral, I. Costs of Tannery Waste Treatment, 2005.

[14] BASF, Pocket Book for the Leather Technologist, $4^{\text {th }}$ Edition. 